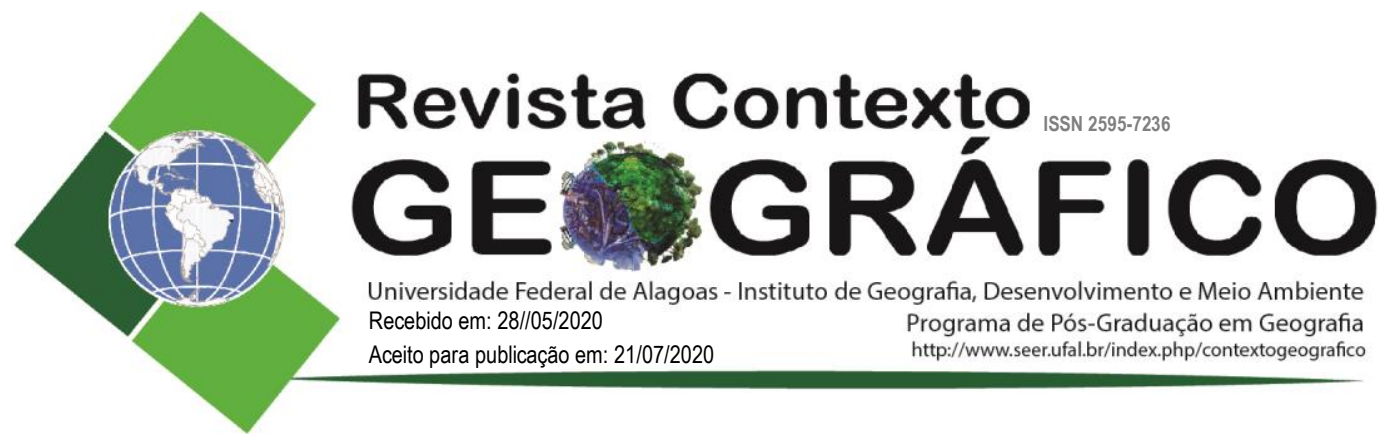

\title{
DINÂMICA ESPAÇO-TEMPORAL E INDICADORES SOCIAIS: ANÁLISE DO CORONAVÍRUS (COVID-19) EM MACEIÓ (AL)
}

\author{
Paulo Henrique Silva de Amorim \\ Mestrando do Programa de Pós-Graduação em Geografia (PPGEO) \\ Universidade Federal de Uberlândia (UFU), MG, Brasil \\ paulohamr@gmail.com
}

\begin{abstract}
RESUMO - Do global ao local, uma nova praga assola cidades, colocando seus respectivos cidadãos em estado de prontidão. Trata-se da COVID-19, o novo Coronavírus, doença contagiosa que ocupa vertiginosamente os quadros de imprensa e meios digitais nas redes sociais com suas consequências em diferentes territórios. Nesse contexto, o presente trabalho tem como objetivo analisar a dinâmica espaço-temporal da COVID-19 em Maceió (AL) entre $14 / 04 / 2020$ e 20/05/2020, a fim de verificar as interações entre seu padrão de ocorrência e a variabilidade dos indicadores sociais. A metodologia utilizada consistiu na realização de análises espaço-temporal dos casos e óbitos confirmados da COVID-19 por distritos sanitários, seguida de uma análise baseada em diferentes critérios - renda, raça/cor, população absoluta e situação hospitalar - contribuindo com o desenvolvimento de políticas públicas para o município. Os resultados mostraram que o comportamento espaço-temporal da COVID-19 entre o período analisado se caracterizou por clusters de alta incidência e persistência nos distritos sanitários de menor renda no município. O Distrito Sanitário 07 foi o que mais cresceu com casos registrados para COVID-19 no período analisado - 671 confirmações e 31 óbitos -, causando interferência direta entre os bairros adjacentes. Também se observou que o vírus acomete, principalmente, negros e pardos em Maceió.
\end{abstract}

Palavras-chave: COVID-19; Distritos sanitários; Indicadores sociais.

\section{SPATIO-TEMPORAL DYNAMICS AND SOCIAL INDICATORS: ANALYSIS OF THE CORONAVIRUS (COVID-19) IN MACEIÓ (AL)}

\begin{abstract}
From global to local, a new plague plagues the cities, putting their respective citizens in a state of readiness. It's case of COVID-19, the new Coronavirus, a contagious disease that occupies vertiginously the press and digital media on social networks with its consequences in different territories. In this context, the present study aims to analyze the spatial-temporal dynamics of COVID-19 in Maceió (AL) between 4/14/2020 and 5/20/2020, in order to verify the interactions between its pattern of occurrence and the variability of social indicators. The methodology used consisted of carrying out spatio-temporal analyzes of confirmed cases and deaths of COVID-19 on the health districts, followed by an analysis based on different criteria - income, race/color, absolute population and hospital situation contributing to the development of public policies for the municipality. The results showed that the spatial-temporal behavior of COVID-19 between the analyzed period was characterized by clusters of high incidence and persistence in the lower income sanitary districts in the municipality. The Health District 07 was the one that grew the most with cases registered for COVID-19 in the analyzed period - 671 confirmations and 31 deaths -, causing direct interference between adjacent neighborhoods. It was also observed that the virus affects mainly people blacks and browns in Maceió.
\end{abstract}

Keywords: COVID-19; Health districts; Social indicators. 


\section{INTRODUÇÃO}

Mal foi iniciada a segunda década do novo milênio e já foram deflagradas mudanças em escala mundial, instigando pesquisadores que analisam as transformações que delas se originam, como também afetando de forma significativa sujeitos em diferentes níveis de escala. Do global ao local, mais uma praga assola cidades, colocando seus respectivos cidadãos em estado de prontidão. Trata-se da COVID-19, o novo Coronavírus, doença contagiosa que ocupa vertiginosamente os quadros de imprensa e dos meios digitais nas redes sociais com suas consequências em diferentes territórios e segmentos sociais.

A introdução e a transmissão precoce da COVID-19 no Brasil configuram-se como um grande desafio, principalmente no aspecto econômico e social, tornando emergencial a adoção de políticas públicas em prol dos grupos e classes mais vulneráveis em meio à pandemia. $\mathrm{O}$ primeiro caso do vírus foi registrado no Brasil em 26 de fevereiro de 2020, no maior centro econômico e populacional, São Paulo. E em 08 de março de 2020 foi confirmado o primeiro caso de COVID-19 na capital e maior cidade do Estado de Alagoas, Maceió. De acordo com o boletim do Ministério da Saúde (2020) que trata sobre a COVID-19, até 19 de maio de 2020 o número de casos confirmados no Estado de São Paulo era de 65.995 com 3.029 óbitos, diferente de Alagoas que contava com 4.316 casos e 231 óbitos.

Maceió, que é capital do Estado e faz parte da Região Metropolitana homônima, apresentava até 20 de maio do presente ano 3.632 casos confirmados e 162 óbitos. Infelizmente, no momento da publicação deste artigo os números possivelmente serão superiores em função da velocidade do contágio causado pela COVID-19, somada ao aumento no número de testes realizados em território nacional. É importante destacar que as projeções da evolução da COVID-19 em diversas partes do mundo vêm sofrendo modificações em função das constantes atualizações diárias com base em critérios de análise e no refinamento de modelos estatísticos utilizados.

Considerando as tendências a nível internacional, antecipa-se que é desafiador e inimaginável a quantidade real do número de casos da COVID-19 no país, algo que está declaradamente distante de representar algo remotamente próximo ao auge da pandemia em território nacional. Entretanto, por mais que esses dados não representem a real dimensão do cenário brasileiro, ainda assim eles servem como indicadores de grande relevância para analisar as múltiplas facetas de um país marcado pela ausência de direitos civis que geram consequências irreparáveis resultante de desigualdades sociais.

Identificar a origem dos focos, apontar possíveis justificativas e estabelecer medidas mitigadoras constitui-se como um desafio de grande relevância para a contenção do avanço de uma pandemia, exigindo uma análise mais aprofundada que aborde um conjunto de dados que vão desde o aspecto econômico, social e epidemiológico, sobretudo em sua dimensão espacial. Nesse sentido, o objetivo do presente artigo constitui-se em realizar uma análise acerca da pandemia da COVID-19 na cidade de Maceió (AL) a partir da dinâmica espaço-temporal. Como objetivos específicos: [1] avaliar a variabilidade dos indicadores sociais nos distritos sanitários de Maceió; [2] e suas relações com a propagação desde a fase inicial da doença contribuindo com o desenvolvimento de políticas públicas para o município.

\section{MATERIAIS, MÉTODOS E ÁREA DE ESTUDO}

De acordo com o Atlas do Desenvolvimento Humano do Brasil (2013) com base no censo de 2010, Maceió (Figura 01) é o primeiro município no ranking de Índice de Desenvolvimento Humano (IDH) no Estado de Alagoas com 0,721, enquanto no ranking nacional encontra-se na posição de $1266^{\text {a }}$. Segundo dados do IBGE, a população estimada de Maceió para o ano de 2019 é de 1.018.9948 habitantes, representando aproximadamente $44 \%$ de todo o estado.

Não obstante, o município apresenta-se por uma série de fatores que o tornam ainda mais 
complexos do ponto de vista de uma análise social. No estudo de Alencar (2007), observou-se que $10 \%$ da população corresponde a $41 \%$ de toda a renda de Maceió. Outro destaque dar-se-á com relação ao indicador social relativo ao esgotamento sanitário, a partir do qual constatou-se que, até 2004, somente $24 \%$ da população da cidade era atendida, de acordo com a Companhia de Saneamento de Alagoas (CASAL), revelando clusters na capital, que contribuem incisivamente na leitura de uma cidade marcada por graves contrastes sociais e econômicos.

Para o desenvolvimento da pesquisa, foram utilizadas como base metodológica as seguintes etapas: [1] levantamento de dados ligados à COVID-19 no município de Maceió, obtidos através dos Boletins Epidemiológicos divulgados on-line diariamente (casos hospitalizados em enfermaria, em UTI, óbitos, casos confirmados e distritos sanitários de ocorrência por data); [2] espacialização dos dados municipais de acordo com a escala temporal até o dia 14/04/2020 e até o dia 20/05/2020; [3] análise com base nos indicadores sociais (rendimento por distrito sanitário, raça/cor e população) da ocorrência dos casos da COVID-19 como instrumento de análise para a realização de intervenções, traduzidas como políticas públicas, indicando a relação desses fatores com a suscetibilidade e a vulnerabilidade que se assiste no município em questão.

Figura 1. Mapa de Localização do Município e dos Distritos Sanitários - Maceió (AL)

\section{MAPA DE LOCALIZAÇÃo DISTRITOS SANITÁRIOS DE MACEIÓ (AL)}
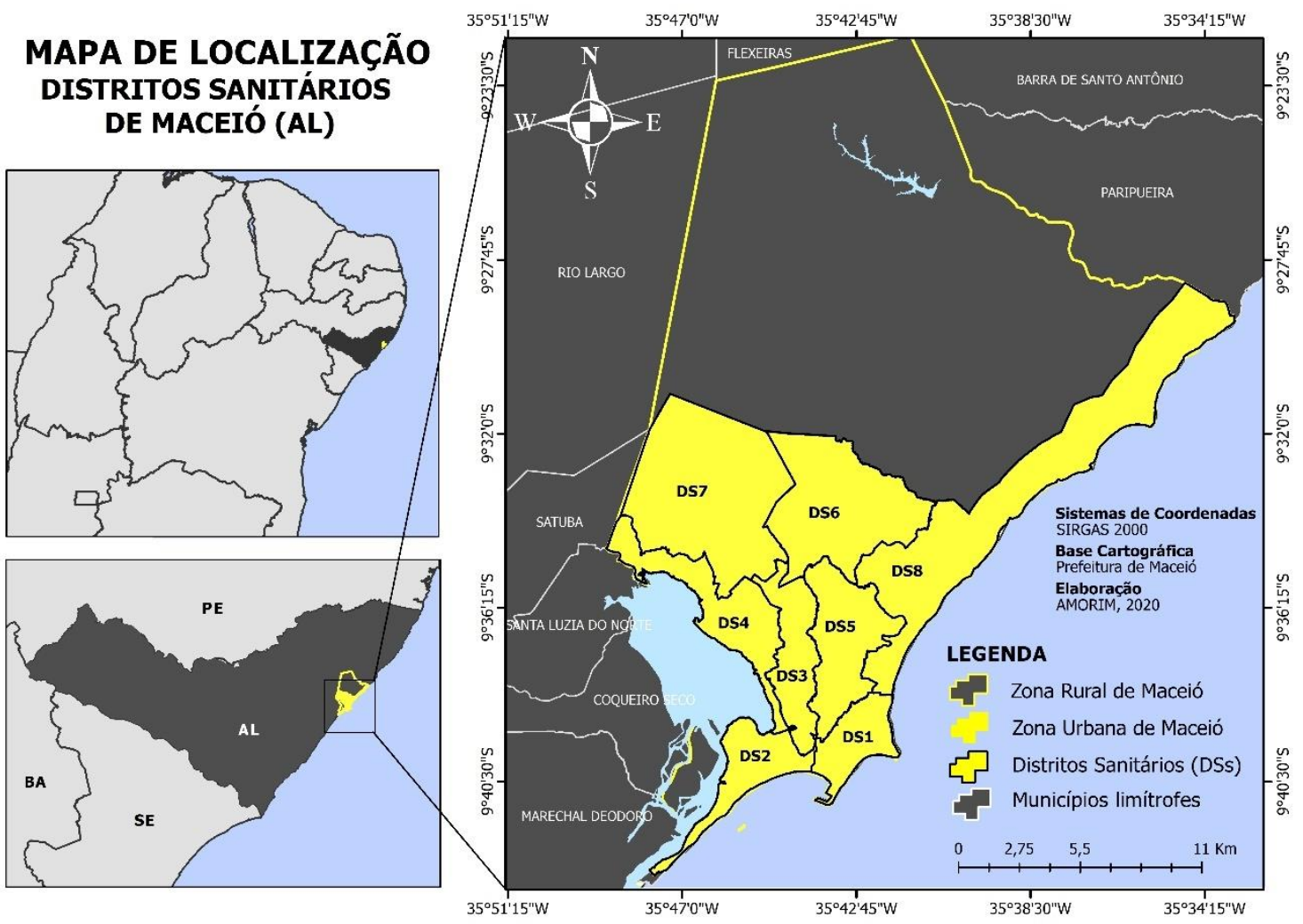

Elaboração: Autor (2020)

Como ponto de partida, utilizou-se como base o dia 15/03/2020, período em que fora iniciado pela Secretaria Municipal de Saúde a divulgação do Boletim Epidemiológico on-line, facilitando e tornando transparente o boletim com o número de casos junto à população local. Também foi utilizado como recorte temporal o dia 14/04/2020 como referência, uma vez que foi somente a partir desta data que se iniciou a divulgação dos casos confirmados para COVID-19 a partir dos Distritos Sanitários (DS) de residência. Por fim, utilizou-se o dia 20/05/2020 como período final do recorte temporal a fim de estabelecer comparações entre os dois períodos.

P. $16-30$

PÁGINA 18 
É importante destacar que além de Maceió, também foi necessário levantar o número de casos no município de Rio Largo por vários fatores, a saber: 1) constitui-se como município limítrofe de Maceió; 2) encontra-se na terceira posição no ranking populacional, ficando atrás somente da capital (Maceió) e de Arapiraca, interior do Estado; 3) compõe a quarta maior densidade demográfica do Estado; 4) aumento do número de casos de COVID-19 até o dia 20/05/2020, período final de análise do presente estudo; 5) interação espacial entre as duas cidades, que vão muito além da proximidade, mas com base nas relações de trabalho (formal e informal), acesso ao hospital regional e metropolitano; além da única rodovia que permite acesso à capital, representada pela Av. Lourival de Melo Mota. Todas essas assertivas caracterizam uma rede urbana conurbada com episódios diários de migração pendular.

Dessa maneira, foram realizadas análises temporais de densidade do número de casos de acordo com os Distritos Sanitários (DS), utilizando o Boletim Epidemiológico Municipal de dois períodos: até 14/04/2020 e até 20/05/2020, com o objetivo de analisar a evolução da densidade do número de casos confirmados na capital. Para esses dados, utilizou-se o software ArcGis 10.4, a partir do qual foram elaborados os mapas a fim de garantir uma melhor representatividade espacial. É importante destacar ainda que os pontos plotados no mapa tiveram como base o Distrito Sanitário e não do bairro do indivíduo que contraiu a COVID-19, sendo esta última uma informação ainda não disponível nos boletins disponibilizados pela Secretaria Municipal de Saúde local.

Em relação à análise de evolução da COVID-19 no município, realizou-se a subtração do número de casos/óbitos por distrito sanitário com base no seguinte recorte temporal: dados até 14/04/2020 (P1) e até 20/05/2020 (P2), totalizando 34 dias de análise, como apresentado na fórmula a seguir: $\mathrm{PG}=\mathrm{P} 2-\mathrm{P} 1$

Onde,

PG representa o período global de análise

$\mathrm{P} 1$, representa o período de 14 de abril de 2020

$\mathrm{P} 2$, representa o período de 20 de maio de 2020.

\section{A GEOGRAFIA NO CENÁRIO DA COVID-19: DINÂMICA ESPAÇO-TEMPORAL}

O primeiro caso confirmado de COVID-19 em Maceió ocorreu 11 dias após o primeiro registro oficial em território brasileiro, em 26 de fevereiro de 2020. De acordo com a Secretaria Municipal de Saúde, o primeiro registro na capital tratava-se de um homem de 42 anos que havia voltado recentemente da região mais afetada da COVID-19, Lombardia, no norte da Itália (GAZETA WEB, 2020). Desde então, a prefeitura do município tem elaborado e divulgado, de forma conjunta com a Secretaria da Saúde, a publicação de Boletins Epidemiológicos Informativos Diários com informações relativas à disseminação do vírus na capital alagoana.

Nove dias após a primeira confirmação da COVID-19 em Maceió, o prefeito da cidade anunciou via Diário Oficial do Município em 17 de março de 2020 o primeiro decreto sob o $\mathrm{N}^{\circ}$ 8846 com medidas temporárias de combate e prevenção à Pandemia de COVID-19 no município. Apesar de restringir somente alguns grupos de risco de atividades laborais, como idosos, portadores de doenças cardíacas e pessoas que estiveram no exterior, pode-se afirmar que o decreto foi falho, uma vez que todas as atividades continuavam acontecendo em estado de normalidade em toda praticamente toda a cidade, ignorando todas as recomendações emitidas pela Organização Mundial da Saúde (OMS).

Na semana seguinte após a institucionalização do primeiro decreto municipal, foi anunciado um segundo decreto, registrado sob o $\mathrm{N}^{\circ} 8853$, de 23 de março de 2020, com determinações de caráter emergencial, a saber: suspensão das atividades educacionais em todas as escolas da Rede 
de Ensino Fundamental público e privada pelos próximos 15 dias; fechamento por tempo indeterminado de bares, restaurantes, lanchonetes e conveniências. Pode-se afirmar que este decreto somente foi institucionalizado após a cidade apresentar uma evolução significativa no número total de casos, registrando oito confirmações de COVID-19 até a presente data.

Nesse período, já com a adoção da política de distanciamento social adotado pela cidade, podia ser observado na semana entre 23 e 29 de março o percentual máximo de $61 \%$, valor acima da média nacional que estava próximo de 60\% (G1 ALAGOAS, 2020), como mostra a Figura 2.

Figura 2. Índice de Isolamento Social em Maceió, Alagoas e Brasil

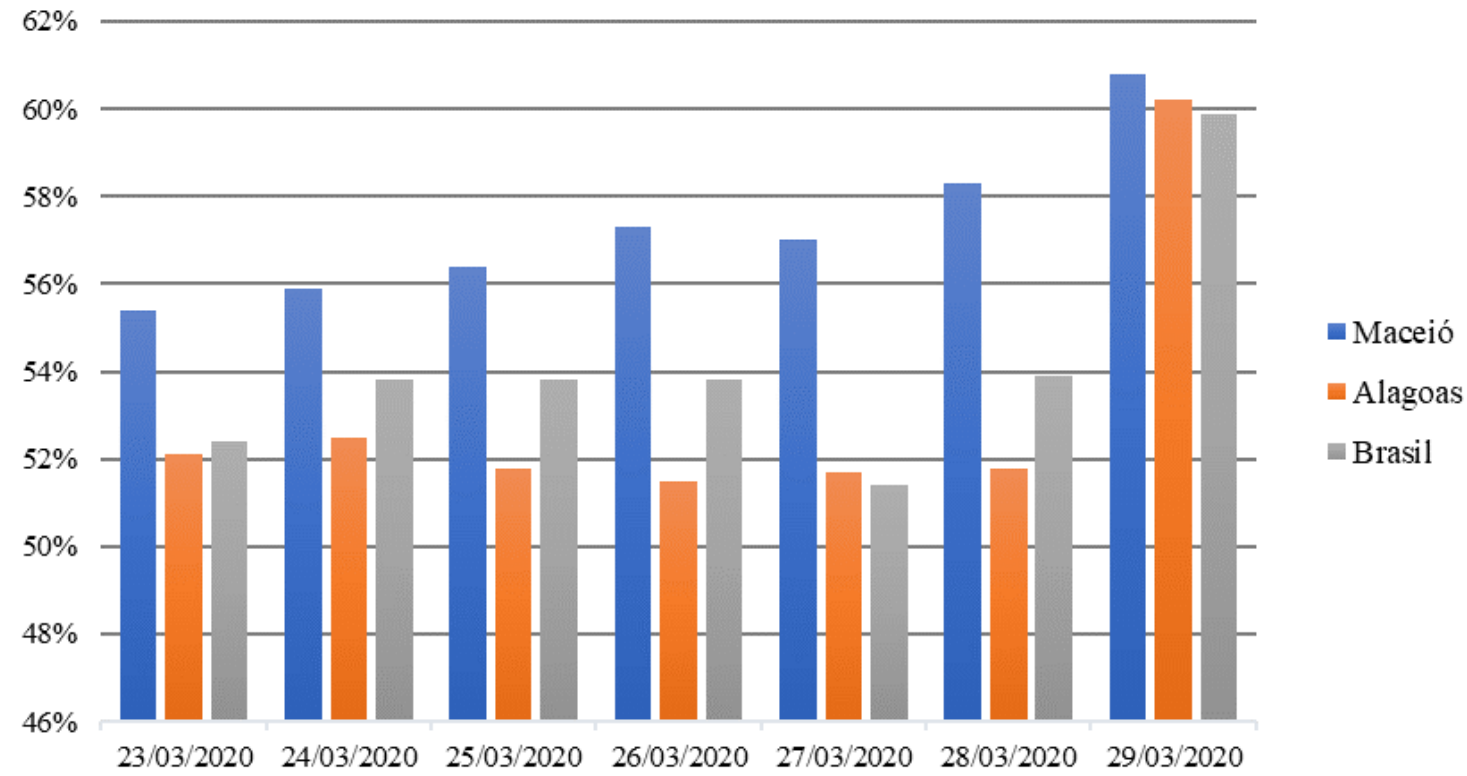

Fonte: In Loco (2020). Acesso em 21 de maio de 2020

O último decreto, seguramente o mais rigoroso com relação aos anteriores, ocorreu um mês depois, em 22 de abril, no qual foi declarado o estado de calamidade da saúde pública em âmbito municipal. O decreto em questão, registrado sob o $\mathrm{N}^{\circ} 8869$, restringiu e determinou quais serviços essenciais estavam autorizados a funcionar na cidade, a saber:

Art. $5^{\circ}$ São considerados serviços essenciais, para fins do Estado de Calamidade em Saúde Pública ora decretada, aqueles indispensáveis ao atendimento das necessidades inadiáveis da comunidade, assim considerados aqueles que, se não atendidos, colocam em perigo a sobrevivência, a saúde ou a segurança da população, tais como:

I) assistência à saúde;

II) atividades de segurança privada;

III) transporte público de passageiros e transporte de passageiros por táxi ou aplicativo;

IV) produção, distribuição, comercialização e entrega de produtos de higiene, saúde, alimentos e bebidas.

(MACEIÓ. Decreto N 8869, de 22 de abril de 2020)

Dessa maneira, mesmo após a sanção de vários decretos, a maioria deles tardios do ponto de vista do grande problema que já alertava os órgãos locais, mas que foram ignorados durante bastante tempo, Maceió não escapou do ritmo acelerado como observado em grande maioria dos estados brasileiros, sobretudo nas regiões Norte, Nordeste e Sudeste do país. 
Nessa fase da COVID-19, é de fundamental importância compreender o padrão espacial da disseminação do vírus, identificar os distritos sanitários que concentraram os casos iniciais e analisar as tendências de avanço da COVID-19 na capital. Nesse sentido, foram elaborados mapas com os casos registrados até 14 de abril e até 20 de maio de 2020, como apresentados nas figuras 02 e 03 a seguir. No primeiro período, havia 62 casos confirmados em Maceió, enquanto Rio Largo apresentava 03 casos confirmados. No segundo período, o número de casos confirmados havia aumentado consideravelmente para 103 casos. Em Maceió o número de casos confirmados havia mais do que dobrado, alcançando 3632 confirmações da COVID em 20 de maio de 2020.

Na figura 03, é possível observar que o distrito sanitário que concentrava a maior incidência no número de casos da COVID-19 era, até 14 de abril, o distrito de número 01, com 20 casos confirmados, considerado um outlier (ponto fora da curva), quando comparado com os demais distritos sanitários do município, que apresentavam até o presente período entre 9 e 12 casos confirmados, como pode ser verificado nos Distritos Sanitários 02, 03 e 07 (Figura 3).

Figura 3. Número de casos de COVID-19 por Distritos Sanitários em Maceió - 14/04/2020

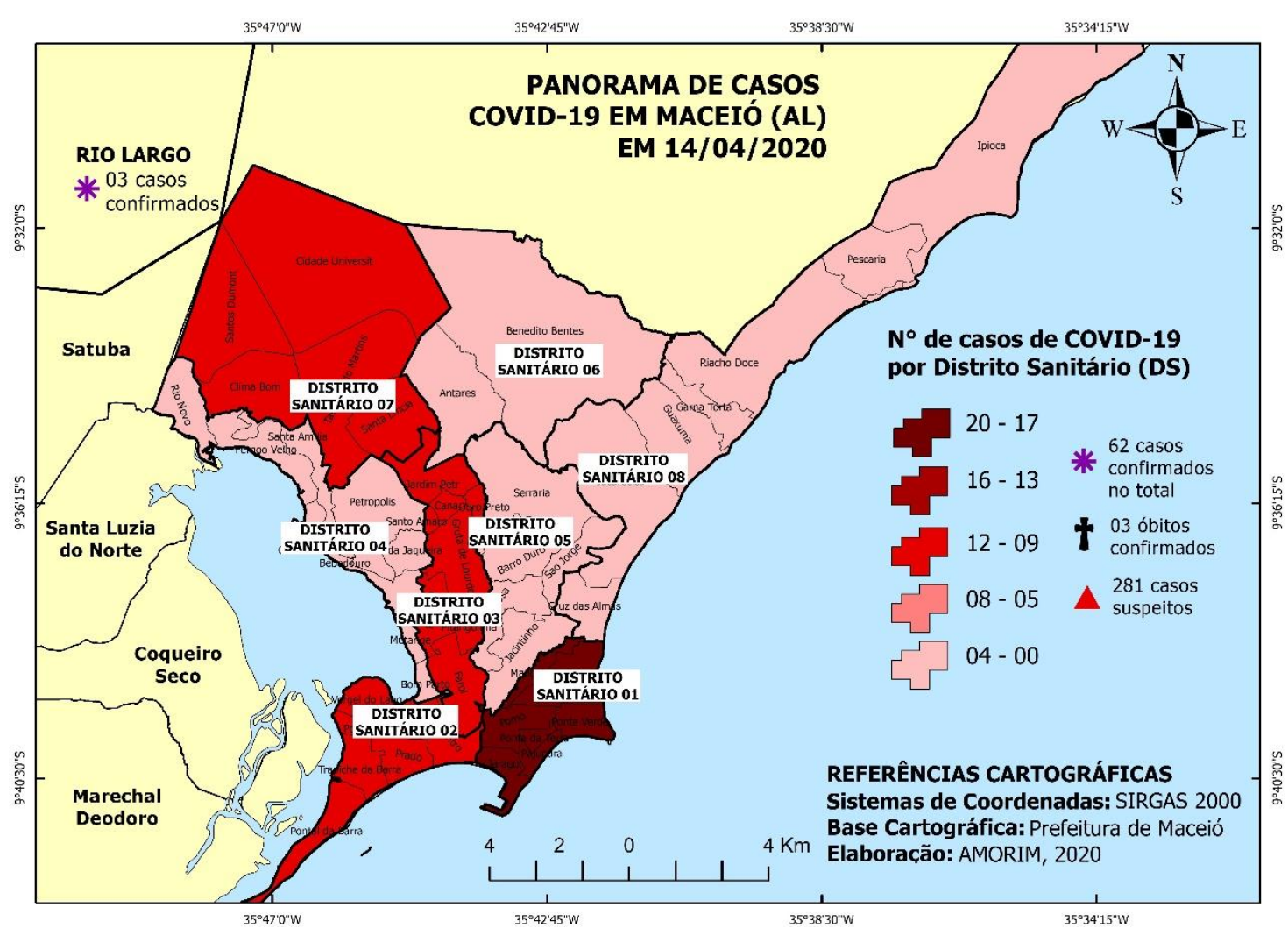

Elaboração: Autor (2020). Fonte: Secretaria Municipal de Saúde (SMS)

Dos oito distritos sanitários, quatro deles apresentavam poucos casos confirmados para a COVID-19, como se verifica nos distritos de número 04, 05, 06 e 08. Uma justificativa para esse desequilíbrio entre os distritos dar-se-á em função de a Secretaria da Saúde Municipal ainda não ter fornecido até o presente período a quantidade adequada de testes junto à população, fato este que dificultou e tornou ainda mais distante de representar algo remotamente próximo ao clímax da pandemia em nível estadual.

Apesar de não apresentar o maior destaque na Figura 02, é de grande importância ressaltar 
também o número de casos no Distrito Sanitário 07, que marca um importante limite entre Maceió e Rio Largo, por onde há grande conectividade entre os dois municípios. A título de curiosidade, o município de Rio Largo é, atualmente, conurbado com os bairros Santos Dumont e Cidade Universitária (Maceió), pertencentes ao Distrito Sanitário 07, fato este que remonta ao único acesso rodoviário que o município possui com a capital, através da Avenida Lourival Melo Mota. O transporte rodoviário entre os dois municípios ocorre de forma abundante com a oferta de transporte público intermunicipal e vans regulares e complementares que desloca uma parcela significativa da população rio-larguense em direção à capital.

De acordo com a Figura 4, Rio Largo apresenta em 20/05/2020 103 casos confirmados, diferente da análise espacial realizada em 14/04/2020, quando apresentava somente três casos confirmados para a COVID-19. Um dado alarmante é observado no surgimento de óbitos, situação essa que não se apresentava na anterior.

Figura 4. Número de casos de COVID-19 por Distritos Sanitários em Maceió - 20/05/2020

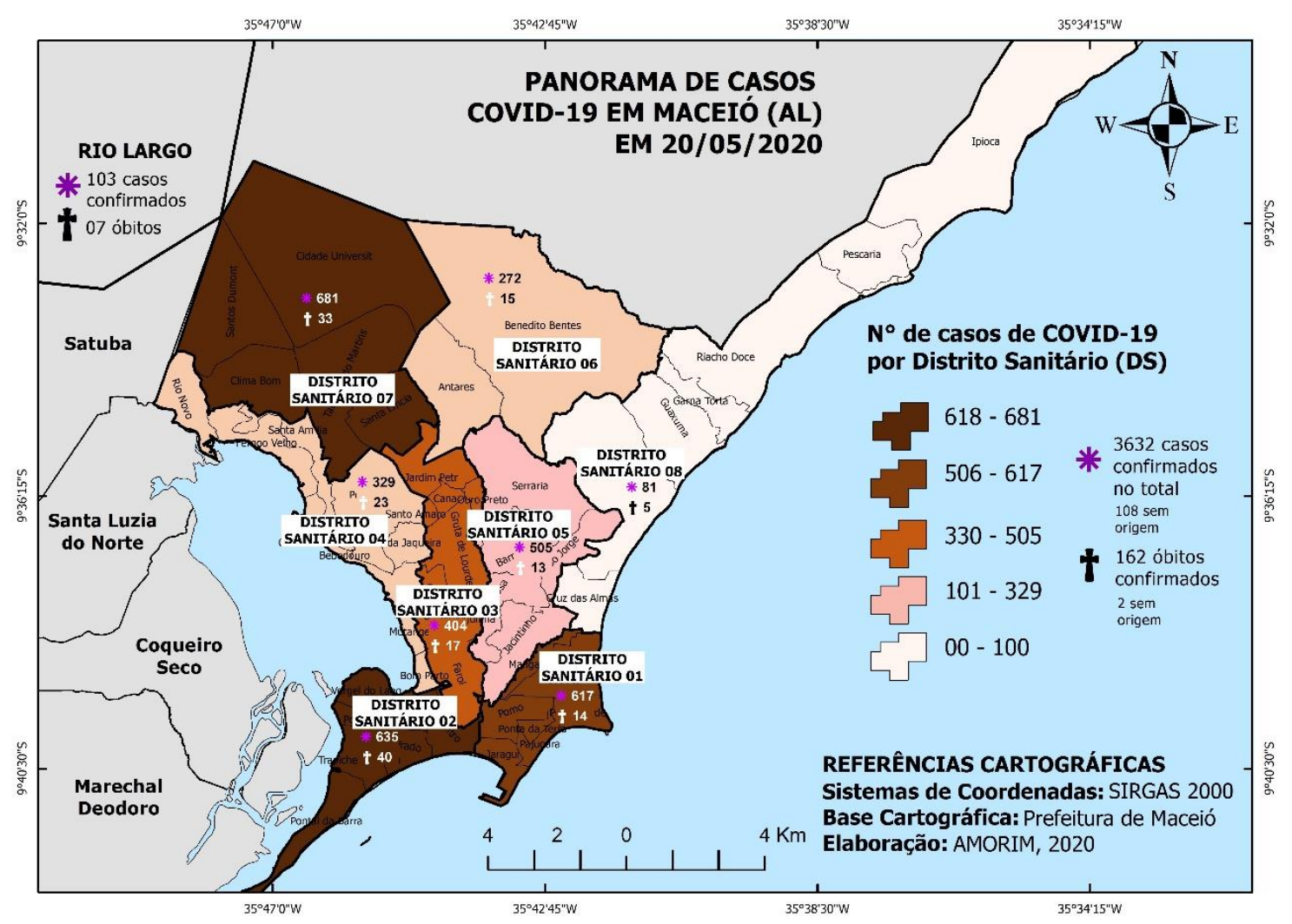

Elaboração: Autor (2020). Fonte: Secretaria Municipal de Saúde (SMS)

Dos oito distritos sanitários, agora, três deles passam a ganhar destaque na Figura 03, diferente do que ocorrera na Figura 02, quando somente o Distrito Sanitário 01 concentrava a maior parte dos casos confirmados para a COVID-19. Para o período até 20/05/2020, verifica-se um significativo avanço no número de casos em toda Maceió, que passa a registrar 3632 casos confirmados até o presente período de análise, um valor alarmante, considerando o primeiro período, quando toda a cidade apresentava 62 casos.

Essa diferença na quantidade de casos entre 14/04/2020 e 20/05/2020 é observada a partir da Tabela 1, que apresenta em quais distritos sanitários houve maior crescimento. Esses dados são de grande importância para observar a velocidade da propagação que o vírus teve em apenas 34 
dias, conferindo à Secretaria Municipal de Saúde a adoção emergencial de ações efetivas no combate à COVID-19 em Maceió, que vão além das alterações já realizadas no último decreto $\mathrm{N}^{\circ}$ 8869, de 22 de abril de 2020. Essas medidas são necessárias dadas as variáveis que envolvem o surgimento do vírus somada à expectativa por respostas do sistema científico no combate à pandemia. Assim, entende-se que a única e possivelmente medida mais efetiva, pelo menos até a data de publicação deste trabalho, no combate ao COVID-19 é representada pelo isolamento social das famílias e, em particular, dos indivíduos infectados.

Tabela 1. Crescimento no número de casos confirmados de COVID-19 por Distritos Sanitários entre 14/04/2020 e 20/05/2020 para o município de Maceió (AL)

\begin{tabular}{cccc}
\hline \multirow{2}{*}{ Distrito Sanitário (DS) } & \multicolumn{2}{c}{ Casos confirmados } & \multirow{2}{*}{ Crescimento em 34 dias } \\
\hline Distrito Sanitário 01 & 20 & 617 & 597 novos casos \\
Distrito Sanitário 02 & 11 & 635 & 624 novos casos \\
Distrito Sanitário 03 & 10 & 404 & 394 novos casos \\
Distrito Sanitário 04 & 3 & 329 & 326 novos casos \\
Distrito Sanitário 05 & 2 & 505 & 503 novos casos \\
Distrito Sanitário 06 & 4 & 272 & 268 novos casos \\
Distrito Sanitário 07 & 10 & 681 & 671 novos casos \\
Distrito Sanitário 08 & 2 & 81 & 79 novos casos \\
\hline TOTAL & $\mathbf{6 2}$ & $\mathbf{3 6 3 2}$ & $\mathbf{3 5 7 0}$ novos casos \\
\hline
\end{tabular}

Elaboração: Autor (2020). Fonte: Secretaria Municipal de Saúde (2020)

Ademais, cumpre apontar que essa difusão do COVID-19 está, em grande parte, relacionada à amplitude de interação entre mais alguns distritos sanitários do que em outros, o que não difere do município de Maceió em termos gerais. Sobre essa questão, os geógrafos Sposito \& Guimarães (2020) destacam que "os dados sobre a difusão da COVID-19 no país indicam que se trata de um modelo hierárquico, fortemente relacionado com as interações espaciais existentes na rede urbana brasileira". Dessa maneira, frisa-se que esse processo de interação faz parte da realidade de Maceió, bem como se origina a partir dela o processo de difusão da COVID-19 nos demais municípios que compõem a Região Metropolitana, apresentada mais adiante.

De acordo com a Tabela 1 acima, observa-se que o número de casos confirmados para COVID19 é diferente nos dois períodos de análise. No entanto, já é possível observar que na primeira data, 14/04/2020, alguns distritos sanitários ganham maior destaque em relação aos demais. É o caso dos distritos sanitários 01,02 e 07 . Ao mesmo tempo, esse cenário também se repete no segundo período de análise, 20/05/2020, no qual os mesmos distritos mencionados mantêm o ritmo de contágio com um número bem maior de casos confirmados. Já na Tabela 2, verifica-se que os óbitos confirmados caminham para a mesma direção, reforçando o exposto em relação aos distritos sanitários 01, 02 e 07.

Pode-se associar o presente cenário no Distrito Sanitário 02 e 07 a dois fatores: o primeiro está relacionado ao fato de estes distritos se caracterizarem como responsáveis por um adensamento populacional significativo, o que eleva ainda mais a possibilidade de contágio. O segundo fator diz respeito somente ao Distrito Sanitário 02, do qual faz parte o bairro Centro, responsável pela maior circulação entre pessoas em toda a cidade, direcionando todo o fluxo de automóveis, transporte público, trabalhadores formais e informais, entre outros 
Tabela 2. Surgimento e crescimento no número de óbitos confirmados de COVID-19 por Distritos Sanitários entre 14/04/2020 (P1) e 20/05/2020 (P2) para o município de Maceió (AL)

\begin{tabular}{cccc}
\hline \multirow{2}{*}{ Distrito Sanitário (DS) } & \multicolumn{2}{c}{ Óbitos confirmados } & \multirow{2}{*}{ Crescimento em 34 dias } \\
\hline Distrito Sanitário 01 & 1 & 14 & 13 novos óbitos \\
Distrito Sanitário 02 & - & 40 & 40 óbitos \\
Distrito Sanitário 03 & - & 17 & 17 óbitos \\
Distrito Sanitário 04 & - & 23 & 23 óbitos \\
Distrito Sanitário 05 & - & 13 & 13 óbitos \\
Distrito Sanitário 06 & - & 15 & 15 óbitos \\
Distrito Sanitário 07 & 2 & 33 & 31 novos óbitos \\
Distrito Sanitário 08 & - & 5 & 5 óbitos \\
\hline TOTAL & $\mathbf{3}$ & $\mathbf{1 6 2}$ & $\mathbf{1 5 9}$ novos casos \\
\hline
\end{tabular}

Elaboração: Autor (2020). Fonte: Secretaria Municipal de Saúde (2020)

Esse último fator é mais significativo na fase inicial da pandemia, que acomete, inclusive o município de Rio Largo, pois, como já apontado anteriormente, é através de uma única rodovia que a população alcança a capital. No entanto, além do acesso pela rodovia, o itinerário realizado pelo modal ferroviário também direciona uma parcela significativa da população de Rio Largo. De acordo com a Companhia Brasileira de Trens Urbanos, o transporte ferroviário de Maceió possui 34,4 quilômetros de extensão, e é responsável pela interligação da capital com os municípios de Rio Largo e Satuba, transportando uma média de 11 mil passageiros por dia (CBTU, 2015).

Nesse sentido, atesta-se o quanto a mobilidade urbana também se apresenta como um instrumento facilitador na difusão da COVID-19, conferindo desafios que caminham em direção aos demais municípios da Região Metropolitana. Pois, tal como acontece com a capital do Estado, no município de Rio Largo, conurbado com Maceió, também houve um aumento significativo do vírus, passando de 3 para 103 casos confirmados em 34 dias de análise. Em relação aos óbitos, também não foi diferente: de 0, em 14 de abril, para 3 óbitos, em 20 de maio.

Em relação à Região Metropolitana de Maceió (RMM), o governador de Alagoas atualizou um Decreto Estadual no dia 21 de maio de 2020 (Figura 5) determinando que autoridades locais intensificassem a fiscalização nos municípios que apresentavam maior incidência de COVID-19 com o objetivo de diminuir a curva do contágio na região.

Como justificativa para a atualização do decreto, o governador do Estado tomou como base o levantamento realizado pela Secretaria Estadual de Saúde, a partir do qual foi identificado que a Região Metropolitana de Maceió respondia, sozinha, por 76\% dos casos de COVID-19 em todo o estado, um percentual considerado elevado quando comparado com a população total de Alagoas: 3.322,114 milhões de habitantes (IBGE, 2019).

Entre as principais alterações no decreto, destacam-se, além da intensificação da fiscalização já mencionada, a suspensão imediata do serviço de transporte rodoviário intermunicipal de passageiros, seja ele regular ou complementar, bem como os de serviço receptivo. Essas medidas tem validade, segundo o decreto, até o dia 31 de maio de 2020 - uma validade curta, mesmo com um crescimento cada vez mais acentuado da COVID-19 em todo o estado. Todavia, qualquer que seja a proporção na combinação das ações determinadas pelos órgãos municipais ou estaduais, a multiplicação espantosa do número de confirmações e de óbitos da Região Metropolitana é apenas uma questão de tempo.

E tempo, na realidade, é um elemento de altíssima credibilidade no combate à COVID-19. Expandir a capacidade de testagem e de atendimento nos distritos sanitários a fim de dissolver o número de casos graves num período mais extenso para evitar intensificar a bolha que já está prestes a estourar no sistema de saúde são, no presente momento, os principais objetivos dos gestores de saúde em escala global. Resta saber o quanto Maceió terá condições de aproveitar desse tempo. 
Figura 5. Atualização do decreto $\mathrm{N}^{\circ} 69.722$, de 04/05/2020 pelo governador de Alagoas

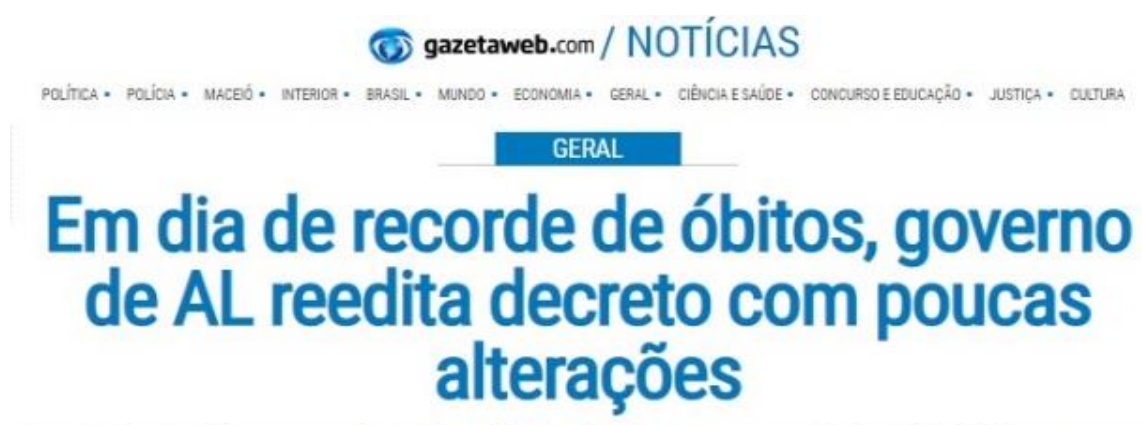

Sociedade Alagoana de Infectologia havia recomendado o lockdown, mas o pleito apresentado pelos médicos foi ignorado

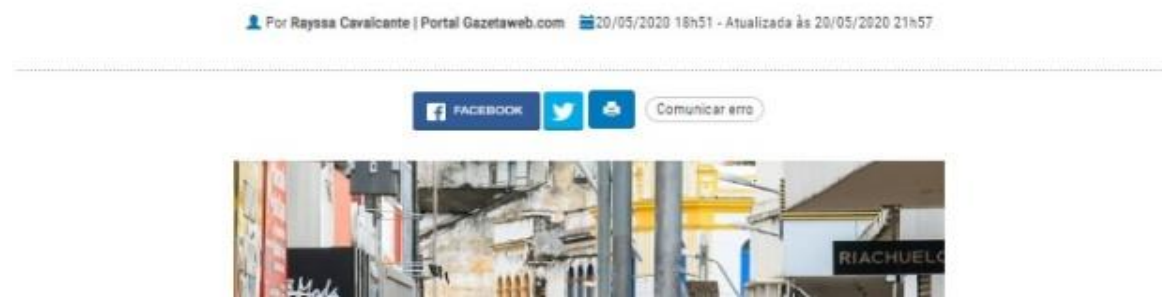

Fonte: GazetaWeb. Acesso em 24 de maio de 2020

\section{CONTRIBUIÇÃO DOS INDICADORES SOCIAIS X COVID-19 EM MACEIÓ (AL): UMA RELAÇÃO DE CAUSALIDADE}

A instalação da pandemia como um fenômeno de multidões em Maceió, sobretudo nos distritos sanitários mais periféricos, vem pouco a pouco elucidando características da difusão da COVID-19 no estado alagoano. Ao que tudo indica, o principal responsável pela introdução seguida da difusão da COVID-19 foi a elite globalizada (FORTES, 2020), isto é, pessoas que viajam ao exterior ou possui algum tipo de contato com quem esteve viajando, à qual se somaram, supostamente, turistas que visitavam à capital. Isso comprova a razão de os casos se concentrarem, inicialmente, nos distritos sanitários de maior renda, apresentados mais adiante.

Essa característica de caráter socioeconômico da primeira fase de instalação da pandemia em Alagoas pode ser entendida até mesmo na disparidade na quantidade de casos sobre os diferentes distritos sanitários da capital, Maceió. Isso porque, de acordo com a Figura 03, que ilustra a fase inicial da pandemia, vê-se o Distrito Sanitário 01, com 109.806 habitantes (Plano Municipal de Saúde, 2018), tinha 20 casos confirmados. Já o Distrito Sanitário 07, com 268.739 mil habitantes, registrava somente 12 casos. Jatiúca, Pajuçara e Ponta Verde, todos eles com população relativamente menor, completam a lista dos dez bairros que integram o Distrito Sanitário 01 e que também concentrava mais casos.

Esses bairros de classe média alta, sem dúvida, oferecem melhores condições para o isolamento social e a quarentena, além de ter um acesso mais privilegiado à rede de saúde, pois, basta localizar onde estão esses bairros: na beira-mar de Maceió $^{1}$. A notificação, pelo menos inicialmente, tende a apresentar um volume maior, mas terá redução mais rapidamente em função das melhores condições de renda que a maioria da população do distrito apresenta em relação aos bairros que integram os demais distritos sanitários da capital, os quais possuem como única alternativa o serviço de saúde público.

O fato é que a confirmação dessa hipótese já é ratificada no segundo período de análise deste estudo, após o período de 34 dias, em 20/05/2020. Tratam-se de taxas de transmissão e principalmente de letalidade muito mais aceleradas nos Distritos Sanitários 02 e 07 de Maceió, 
enquanto o mesmo não acontece com o Distrito Sanitário 01 (Figura 4).

Essas afirmações são apresentadas na Tabela 3, na qual busca-se avaliar essas questões pelo prisma da distribuição de renda.

Tabela 3. Distribuição de renda e população por Distrito Sanitário no município de Maceió (AL)

\begin{tabular}{ccc}
\hline Distrito Sanitário (DS) & População (2016) & Renda familiar média (2010) \\
\hline Distrito Sanitário 01 & 109.806 & $\mathrm{R} \$ 4.471,72$ \\
Distrito Sanitário 02 & 110.936 & $\mathrm{R} \$ 1.780,33$ \\
Distrito Sanitário 03 & 75.309 & $\mathrm{R} \$ 3.372,73$ \\
Distrito Sanitário 04 & 106.005 & $\mathrm{R} \$ 1.284,91$ \\
Distrito Sanitário 05 & 179.255 & $\mathrm{R} \$ 2.134,37$ \\
Distrito Sanitário 06 & 122.104 & $\mathrm{R} \$ 1.780,15$ \\
Distrito Sanitário 07 & 268.739 & $\mathrm{R} \$ 1.294,21$ \\
Distrito Sanitário 08 & 41.778 & $\mathrm{R} \$ 1.785,19$ \\
\hline
\end{tabular}

Elaboração: Autor (2020). Fonte: Plano Municipal Assistência Social (2018)

De acordo com a tabela acima, observa-se a diferença da renda familiar entre os Distritos Sanitários é mais evidente no Distrito Sanitário 01. Esse indicador remonta à análise da Figura 2 apresentada nesse estudo, a partir da qual é observada que, quando se trata fatalidade causada pela COVID-19, os números são menores no Distrito Sanitário 01 e bem mais expressivos nos Distritos Sanitários 02 e 07.

Ademais, vê-se o quanto a renda se configura como um fator determinante em tempos de pandemia. Aliás, não somente nesses tempos, mas em toda uma vida, pois há de existir a garantia de um desenvolvimento humano pleno e digno. Um contraste que reforça a desigualdade social vivenciada pela grande maioria da população, e que está diretamente relacionada ao acesso a serviços hospitalares e clínicos, à possibilidade de garantir o distanciamento social, ao acesso à informação, além do acesso aos produtos de proteção (álcool em gel, máscaras, entre outros).

Segundo Vilaça (1986), as classes sociais não estão aleatoriamente distribuídas pelo espaço da cidade. Pelo contrário, a localização dos grupos de renda em determinados bairros da cidade relaciona-se, entre outros aspectos, à diferente capacidade que cada grupo possui de pagar tanto pela casa ou terreno, quanto pelos equipamentos e serviços coletivos.

Como aponta Rodrigues (1988),

Somente os que desfrutam de determinada renda podem morar nas áreas bem servidas de equipamentos coletivos. Os que não podem pagar, são empurrados para as periferias subequipadas, as áreas suburbanas, as áreas centrais deterioradas e para os loteamentos ilegais. (RODRIGUES, 1988, p. 76)

Relacionada à renda, um outro indicador que é reflexo da desigualdade social é a raça/cor. De acordo com os dados divulgados segundo o Boletim Epidemiológico de 20 de maio de 2020, o perfil socio-racial mais acometido entre os óbitos confirmados em Maceió são de pessoas pretas e pardas, totalizando $24 \%$ entre os casos fatais. Já as pessoas de cor branca e amarela respondem por $2 \%$ e $1 \%$, respectivamente. O percentual restante, de $79 \%$, ainda está em in vestigação, pois, de acordo com a Secretaria Municipal de Saúde, essa variável somente passou a ser incluída a partir de 08 de maio de 2020, após determinação do Ministério da Saúde, a pedido da Sociedade Brasileira de Medicina de Família e Comunidade (SBMFC). 
Alguns dos fatores que contribuem para a vulnerabilidade da população negra no Brasil diante do COVID-19 podem ser encontrados no relatório "COVID-19 e desigualdade", pesquisa elaborada por Carvalho \& Xavier \& Pires (2020). A pesquisa tem como recorte temático a renda e não a raça. Porém, de acordo com o levantamento do IBGE para o ano de 2019, dos 13,6 milhões de brasileiros que vivem em extrema pobreza, $75 \%$ deles são negros ou pardos. Segundo o levantamento, quanto mais pobre é a faixa da população, maior é o percentual de pessoas negras.

Entre as características abordadas no trabalho, destacam-se a maior dependência do transporte público, uma maior quantidade de pessoas residindo em um mesmo domicílio, ausência de saneamento básico e acesso restrito aos serviços de saúde. Ainda de acordo com o estudo do IBGE (2019), 67\% da população negra brasileira depende do SUS Por último, existe também um desafio no cumprimento da demanda por isolamento social sem que ocasione no comprometimento da renda familiar ou do emprego, já que a maioria trabalha em atividades que exigem do empregado a presença física, as quais não possuem a cobertura de incentivos e direitos trabalhistas.

De acordo com o estudo Desigualdades Sociais por Cor ou Raça no Brasil elaborado pelo IBGE (2019), existe uma proporção maior de pessoas negras ou pardas que têm a informalidade como meio de trabalho, totalizando $47,3 \%$ das ocupações. Do outro lado, pessoas brancas nessa condição de trabalho representam $34,6 \%$ do total da população ocupada.

Um outro fator que interfere diretamente na fragilidade local é a situação hospitalar. Quanto maior a quantidade de indivíduos internados em UTI ou enfermaria, menor será a capacidade de tratamento realizado pelo sistema de saúde local, sendo, portanto, maior a taxa de fatalidade causada pela COVID-19. É importante destacar que diferentes dos outros fatores apresentados nesse estudo, este é um dado que integra toda Maceió, mas que também influencia diretamente na fragilidade dos distritos sanitários, pois nem todos dispõem da mesma infraestrutura.

Com relação à situação hospitalar dos registros confirmados para COVID-19 em Maceió, observase na Figura 6 um aumento significativo daqueles que necessitaram de internação na UTI.

De acordo com o levantamento, verificou-se um aumento de aproximadamente $263 \%$ dos registros confirmados entre 14 de abril de 2020 e 20 de maio de 2020 (29 casos a mais). Do outro lado, a proporção do número de casos hospitalizados que necessitaram da enfermaria também houve evolução, aumentando 161\% em relação à data anterior (34 casos a mais).

Esses números tomam como base somente os hospitais estaduais e municipais que tratam os casos confirmados para COVID-19, excluindo os casos suspeitos, bem como as outras enfermidades que, em alguns casos, necessitam da enfermaria e da UTI, de acordo com a Secretaria Municipal de Maceió. Além disso, é importante acrescentar que foi inaugurado no dia 16 de maio de 2020 um novo hospital na capital (Hospital Metropolitano) com 200 leitos, sendo 30 deles de UTI e 170 restantes equipados com enfermarias. De acordo com o governador de Alagoas, toda a infraestrutura foi subsidiada com recursos oriundos do próprio Estado, e determinou também que as atividades no hospital tivessem atenção exclusiva para os novos casos do COVID-19.

Um relatório semanal de morbidade e mortalidade emitido pelo Departamento de Saúde e Serviços Humanos dos Estados Unidos (EUA), publicado em 07 de abril de 2020, apontou que o estudo da prática espacial, quando relacionada com o número de casos e mortes de COVID-19, tendem a refletir uma combinação de fatores epidemiológicos e de nível demográfico específicos de cada área, incluindo: 1) o momento exato da introdução da COVID-19; 2) densidade populacional; 3) distribuição da faixa etária; 4) o momento introdutório de ações a fim de amenizar a disseminação do vírus; 5) a realização de testes em massa, com o objetivo de alcançar o diagnóstico de cada paciente suspeito; e 6) intensificação da fiscalização na área em questão. 
Figura 6: Situação Hospitalar em Maceió (AL) - 14/04/2020 e 20/05/2020

Situação Hospitalar em 14/04/2020

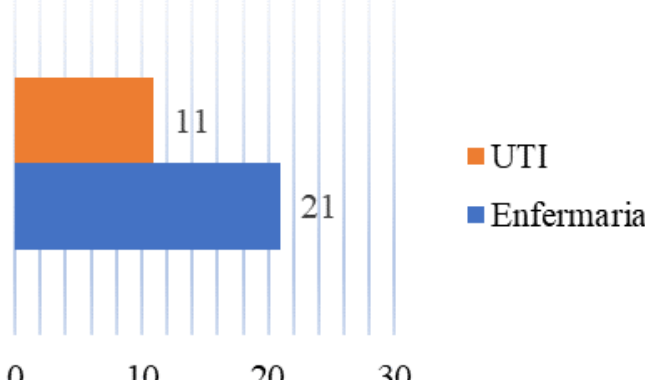

Situação Hospitalar em 20/05/2020

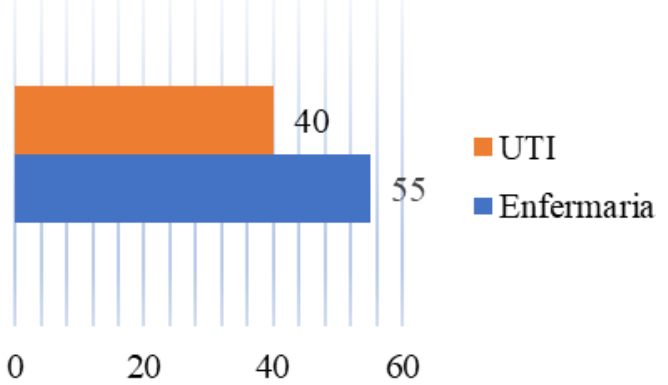

Elaboração: Autor (2020). Fonte: Secretaria Municipal de Saúde de Maceió (2020)

\section{CONSIDERAÇÕES FINAIS}

Em linhas gerais, observa-se o quanto é indispensável a contribuição da ciência geográfica em análises acerca da distribuição espaço-temporal para a COVID-19, como foi tratado no estudo de caso para o município de Maceió, tanto no período inicial quanto mais recentemente, com índices de propagação que se aproximam de um colapso nos serviços de saúde localmente. Além disso, pode-se sintetizar que as reflexões aqui realizadas deixam claro que, à medida em que o vírus se alastra por toda a cidade, há uma concentração principalmente nos distritos sanitários de menor renda e de maior população, ocasionando em desafios que vão muito além das ações já realizadas pelos órgãos competentes locais.

Entre os Distritos Sanitários de Maceió, aquele que merece maior destaque é, sem dúvidas, o Distrito de número 07 , localizado à noroeste do município. Responsável por sete bairros, o distrito é, ainda, o que mais cresce na quantidade casos confirmados (671) e de óbitos (31) para COVID-19 no período analisado, causando interferência direta entre os bairros que integram o distrito sanitário em questão com mais de 268.739 habitantes (IBGE, 2016).

A partir do critério multitemporal, proposto na metodologia, vê-se o quanto os indicadores sociais contribuem de forma significativa em análises espaciais, como no recorte espacial proposto nesse estudo: o município de Maceió, a partir dos Distritos Sanitários. Isso porque, com base nos "números" que se apresentam nos indicadores, visualiza-se um território que aflora em meio à histórica desigualdade social que acomete a maior e mais importante metrópole de todo o estado de Alagoas. São dados socioeconômicos que, quando relacionados com a pandemia da COVID19, traz à tona as assimetrias de bairros da capital com índices alarmantes de vulnerabilidade e suscetibilidade, tornando ainda mais emergente a execução de políticas urbanas de estruturação, que democratize, principalmente, o uso e ocupação do solo nas cidades.

É importante destacar também que tanto os dados de renda familiar quanto os de raça/cor apresentados nesse estudo tiveram como base o último censo realizado pelo IBGE (2010), ou seja, um lapso temporal de 10 anos, o que torna ainda mais desafiador compreender a realidade vivenciada em Maceió, principalmente daqueles se submetem à margem do risco com maior intensidade do que outros - trata-se aqui das pessoas de cor negra daquelas que encontram na periferia a oportunidade única de pagar por uma residência, ainda que os equipamentos urbanos, como principalmente os serviços de saúde, estejam localizados a quilômetros de distância.

Em vista da temática, é importante destacar que o estudo buscou reunir informações que contribuam na ampliação de estudos mais aprofundados. Para tal, segue como sugestão de análises futuras a utilização de unidades que vão além dos distritos sanitários, como bairros e de 
setor censitário, por exemplo. Esses dois, todavia, não chegaram a ser disponibilizados nos boletins epidemiológicos elaborados pela Secretaria Municipal de Saúde. Mesmo assim, acredita-se ser de fundamental importância a representação de dados de acordo com a base censitária e por bairros, pois estes permitiriam a identificação de alterações entre os bairros que registraram o maior número de casos e de óbitos para COVID-19, investigando possíveis cenários acerca da proliferação do vírus de acordo com pontos específicos de contágio, como redes de supermercado, drogarias, bancos e lotéricas, entre outros.

\section{REFERÊNCIAS}

ALENCAR, A. P. A. A expressão das desigualdades urbanas: análise espacial da distribuição da infraestrutura na cidade de Maceió, Alagoas. 2007. 214f. Dissertação (Mestrado em Arquitetura e Urbanismo) - Faculdade de Arquitetura e Urbanismo, Universidade Federal de Alagoas, Maceió, 2007.

BORGES, Herbert. Primeiro caso confirmado de Covid-19 em Alagoas completa um mês. GazetaWEB, Maceió, 08 de abril. 2020. Disponível em: <https://gazetaweb.globo.com/portal/noticia/2020/04/primeirocaso-confirmado-de-covid-19-em-alagoas-completa-um-mes_102377.php>. Acesso em: 21 de mai. 2020.

Carvalho, Laura \& Nassif Pires, Luiza \& de Lima Xavier, Laura. (2020). COVID-19 e Desigualdade no Brasil. 10.13140/RG.2.2.27014.73282.

CAVALCANTE, Rayssa. Em dia de recorde de óbitos, governo de AL reedita decreto com poucas alterações. GazetaWEB. 20 de maio. 2020. Disponível em: <https://gazetaweb.globo.com/portal/noticia/2020/05/_105932.php〉. Acesso em: 21 de maio. 2020.

CBTU. Companhia Brasileira de Trens Urbanos. Sistema Maceió. Disponível em <http://www.cbtu.gov.br/index.php/pt/sistemas-cbtu/maceio>. Acesso em: 27 mai. 2020

FARIAS, Michelle. Índice de isolamento social em Alagoas tem média de 52,47\%. G1 Alagoas. 16 de abril. 2020. Disponível em: <https://g1.globo.com/al/alagoas/noticia/2020/04/16/indice-de-isolamentosocial-em-alagoas-tem-media-de-5247percent.ghtml>. Acesso em: 22 de mai. 2020.

FORTES, Alexandre. A COVID-19 na Baixada Fluminense: Colapso e apreensão a partir da periferia metropolitana do Rio de Janeiro. Espaço e Economia, 2020.

IBGE. Desigualdades sociais por cor ou raça no Brasil. Estudos e Pesquisas. Informação demográfica e socioeconômica, n.41, 2019, 12p.

Estimativas da População Residente para os Municípios e para as Unidades da Federação Brasileiros. IBGE Cidades. Rio de Janeiro, ago. 2019. Disponível em: < http://cidades.ibge.gov.br/xtras/perfil.php?lang=\&codmun=249972>. Acesso em: 21 maio, 2020.

Estimativas da População Residente para os Municípios e para as Unidades da Federação Brasileiros. Referência: até $1^{\circ}$ de julho de 2019. Rio de Janeiro, ago., 2019.

\begin{tabular}{lllll}
\multicolumn{2}{c}{ Estimativas da População Residente para os Municípios, de acordo com os bairros. IBGE } \\
Cidades. Rio de Janeiro, jul. 2016. Disponível em:
\end{tabular} http://cidades.ibge.gov.br/xtras/perfil.php?lang=\&codmun=270430>. Acesso em: 22 mai, 2020.

IN LOCO. Mapa brasileiro da COVID-19. Disponível em: <https://public.tableau.com/profile/inloco.tableau\#!/vizhome/MKTScoredeisolamentosocial/VisoGeral>. Acesso em: 19 mai. 2020.

MACEIÓ. Secretaria Municipal de Assistência Social. Plano Municipal de Assistência Social de Maceió, 2014 a 2017. Disponível em: <http://www.maceio.al.gov.br/wpcontent/uploads/admin/documento/2014/08/PMAS_Macei\%C3\%B3_2014_2017_FINALIZADO-paraupar.pdf.>. Acesso em: 27 mai. 2020.

Secretaria Municipal de Saúde. Informe Epidemiológico. <http://www.maceio.al.gov.br/sms/boletim-coronavirus/>. Acesso em: 27 mai. 2020. 
Secretaria Municipal de Saúde. Plano Municipal de Saúde de Maceió, 2018 a 2021. Acesso em: http://www.maceio.al.gov.br/wp-content/uploads/2018/10/pdf/2018/10/PLANO-MUNICIPALATUALIZADO-EM-18-09-20181.pdf>. Acesso em: 27 mai. 2020.

Decreto n. 8846, de 17 de mar. de 2020. Medidas temporárias de combate e prevenção à Pandemia de COVID-19. Diário Oficial do Município. Maceió, AL, mar 2020.

Decreto n. 8853 de 23 de mar. de 2020. Disciplina Medidas Temporárias de Combate e Prevenção à Pandemia do Coronavírus (COVID-19). Diário Oficial do Município. Maceió, AL, mar 2020 .

Decreto n. 8869 de 22 de abr. de 2020. Dispõe sobre a prorrogação das medidas para enfrentamento do estado de calamidade em saúde pública de importância internacional decorrente do Coronavírus (COVID-19) no âmbito do município de Maceió, e dá outras providências. Diário Oficial do Município. Maceió, AL, abr. 2020.

Documento de Informações (DIB) - Versão Preliminar - Plano Diretor de Maceió - Lei Municipal n. 5486/2005. Diário Oficial do Município, Maceió, AL, dez, 2005.

MMWR, Morbidity and Mortality Weekly Report. Geographic Differences in COVID-19 Cases, Deaths, and Incidence - United States. February 12-April 7, 2020. Rep 2020;69:465-471. DOI: http://dx.doi.org/10.15585/mmwr.mm6915e.

RODRIGUES, A. M. Moradia nas Cidades Brasileiras. São Paulo, Contexto, 1988

SBMFC. Manifestação sobre ausência de dados da COVID-19 desagregados por raça-cor. Disponível em: < https://www.sbmfc.org.br/noticias/gt-de-saude-da-populacao-negra-manifestacao-sobre-ausencia-dedados-da-covid-19desagregados-por-raca-cor/>. Acesso em: 25 mai. 2020.

VASCONCELOS, D. A. L. Turistificação do espaço e exclusão social: a revitalização do bairro de Jaraguá, Maceió - AL, Brasil. Turismo em Análise, v. 16, n. 1, p. 47-67, 2005.

VILLAÇA, F. O que todo cidadão precisa saber sobre habitação. São Paulo: Global, 1986.

\footnotetext{
1 Todavia, há de se considerar assimetrias com relação à análise do Distrito Sanitário 01. Entre elas, destaca-se o caso do bairro Jaraguá que, apesar de não ser considerado um "bairro periférico" no espaço físico urbano, denota-se a fragmentação de uma área no espaço urbano maceioense. Trata-se da Vila dos Pescadores, localizada numa área à beira-mar entre o porto de Jaraguá e alguns armazéns. De acordo com o estudo realizado por Vasconcelos (2005), a condição suburbana que acomete a Vila dos Pescadores é estimada em aproximadamente mil moradores que vivem em condições insalubres e de péssimas condições sócio-econômico-ambientais, em contraste com a circunvizinhança de casas noturnas e de lazer, restaurantes, instituições, entre outros.

${ }^{2}$ Com exceção do Distrito Sanitário 03, pois entre os bairros que o integram, destaca-se o bairro Jardim Petrópolis, cuja renda familiar média por família é de R \$ 10.645,88, valor semelhante do observado nos bairros que compõe o Distrito Sanitário 01, de acordo com o Plano Municipal de Assistência Social (2018). Ademais, uma característica particular do bairro Jardim Petrópolis, é que ele se caracteriza pela abundância de condomínios fechados, dispondo de ampla infraestrutura com equipamentos urbanísticos e de lazer. Assim, conclui-se que, ao somar a renda familiar média deste bairro com os demais que integram o Distrito Sanitário 03, resulta-se num desequilíbrio.
} 